\title{
O PATRIMONIALISMO CARACTERÍSTICO DA ADMINISTRAÇÃO PÚBLICA BRASILEIRA E A GESTÃO DA INFORMAÇÃO E DO CONHECIMENTO DO SETOR PÚBLICO: MEMÓRIA INSTITUCIONAL, PRODIGALIDADE DE TREINAMENTO E CÚPULA ORGANIZACIONAL "POLITIZADA"
}

\author{
PATRIMONIALISM CHARACTERISTICS OF BRAZILIAN PUBLIC ADMINISTRATION AND \\ MANAGEMENT OF INFORMATION AND KNOWLEDGE OF THE PUBLIC SECTOR: \\ INSTITUTIONAL MEMORY, TRAINING AND ORGANIZATIONAL PRODIGALITY SUMMIT, \\ "POLITICIZED"
}

Igor Silva de Menezes

Doutorando em Sociologia e Direito pela Universidade Federal Fluminense. Professor e coordenador do curso de Direito da UNIABEU. E-mail: igormenezesadv@yahoo.com.br

Recebido em: 27/07/2015

Aprovado em: $31 / 03 / 2016$

Doi: $10.5585 / \mathrm{rdb} . v 13 i 6.277$

RESUMO: Este artigo propõe uma reflexão crítica ao modelo institucional brasileiro para ocupação de postos de trabalho no setor público. Inicia-se a discussão apresentando o modelo patrimonialista como característica centenária da gestão pública brasileira. Para tanto, demonstrou-se que autores de historiografia cultural reconhecem as práticas patrimonialistas na gestão institucional como mazela característica congênita da Administração brasileira. Após brevíssima apresentação de situações contemporâneas que ratificam as conclusões históricas, passa-se a breve apresentação descritiva do modelo de gestão da informação e do conhecimento, notadamente como mecanismo de gestão no setor público. Ao final, são apresentadas implicações negativas do modelo de recrutamento patrimonialista largamente utilizado no Brasil sobre a gestão da informação e do conhecimento na Administração pública.

Palavras-Chave: Concurso Público, Patrimonialismo, Gestão da informação e do conhecimento (GIC).

\begin{abstract}
This article proposes a critical reflection to the Brazilian institutional model for occupation of jobs in the public sector. The discussion begins by presenting the patrimonial model as being a 100 year problem which is characteristic of Brazilian public management. It was shown that the cultural historiography of authors recognize the patrimonial practices in institutional management as a long suffering malady which is characteristic of the Brazilian administration. After a very brief presentation of contemporary situations that confirm the historical conclusions, followed by a brief descriptive presentation of information management and knowledge model, to especially show the management mechanism in the public sector. In ending, they present negative implications of the patrimonial recruitment model widely used in Brazil on the management of information and knowledge on public administration.
\end{abstract}

Keywords: Patriomonialismo, Public Administration, Institutional Memory. 


\section{INTRODUÇÃO}

O presente trabalho teve como objeto de reflexão a relação entre o modelo de recrutamento e seleção de pessoal para o setor público e o modelo de gestão do conhecimento idealizado por administradores. A ocupação dos postos públicos, caracterizada pela ausência de impessoalidade como reflexo da cultura patrimonialista secular na administração burocrática brasileira, implica em efeitos infactíveis da aplicação da gestão da informação e conhecimento no setor público.

Incialmente, o estudo procura identificar o problema como característica peculiar brasileira. De tempos mais remotos até os dias atuais, se verificou que é traço característico da nossa cultura organizacional pública a criatividade na criação de mecanismo para pessoalizar as contratações e contornar mecanismos meritocráticos de seleção nas gestões públicas.

Após, apresenta-se uma síntese do que os administradores entendem por gestão da informação e do conhecimento (GIC), especialmente a relevância da aplicação desse mecanismo de gestão no setor público brasileiro.

Ao final, no terceiro capítulo, inferiram-se três potenciais implicações do recrutamento e seleção patrimonialista de pessoal do setor público na gestão do conhecimento. A primeira implicação afetando a "memória institucional" (ou "memória administrativa"). A segunda, tratou do desperdício de treinamento de pessoal contratado a título precário. A terceira cuidou da cúpula organizacional "politizada" e das implicações na descontinuidade de políticas públicas.

\section{O ACESSO AO SETOR PÚBLICO E A PROFISSIONALIZAÇÃO DA ADMINISTRAÇÃO PÚBLICA}

Historicamente, é perceptível a existência de uma cultura organizacional brasileira de gestão da coisa pública. Em termos menos acadêmicos, poderíamos dizer que há um "jeitinho brasileiro" de gerir a coisa pública. Semelhantemente ao que ocorria no passado mais remoto, modelos semelhantes se reproduzem no presente, resistindo firmemente às tentativas de profissionalização da Administração Pública. O Concurso Público figura como resposta à secular cultura patrimonialista de gestão da Administração Pública brasileira. É sobre esse prisma que se desenvolve esse capítulo.

Propondo aprofundar a reflexão e desenvolver a primeira premissa desse artigo, a utilização de métodos da historiografia cultural inclina a perquirir sobre a formação cultural do estado patrimonial brasileiro, e indagar sobre a função institucional do concurso público enquanto sistema méritocrático para ingresso em cargos e empregos públicos. Essa reflexão histórica vai descortinar dois denominadores comuns à cultura de gestão institucional da administração pública brasileira: o patrimonialismo e o concurso público como foco de resistência a esse modelo.

Ao denominado modelo patrimonialista de gestão se contrapõe o modelo burocrático, segundo Bresser-Pereira (2013, p. 1), adotado no Brasil a partir da República. A compreensão do funcionamento desse estado patrimonial, no entanto, deve auxiliar o entendimento do papel do concurso público na gestão institucional brasileira.

De acordo com o dicionário Priberam (2008), o substantivo masculino patrimonialismo designa: "forma de governação que não faz distinção entre o patrimônio 
público e o privado e que baseia a organização social num conjunto de bens com valor de troca".

A visão apresentada por Bresser-Pereira no artigo "Do Estado Patrimonial ao Gerencial", oferece utilíssima descrição panorâmica do Estado brasileiro, nos planos político, administrativo e social, apresentada a seguir em virtude do poder de síntese que essa contribuição pode trazer à compreensão desses dois modelos de administração, a patrimonialista e a burocrática.

\section{Quadro}

Formas históricas de Estado e sociedade no Brasil

\begin{tabular}{|c|c|c|c|}
\hline & $\mathbf{1 8 2 1 - 1 9 3 0}$ & $\mathbf{1 9 3 0}-. .$. & Início \\
\hline Sociedade & Mercantil-Senhorial & Capitalista-Industrial & Pós-Industrial (?) \\
\hline Estado (política) & Oligárquico & Autoritário & Democrático (1985) \\
\hline Estado (administração) & Patrimonial & Burocrático & Gerencial (1995) \\
\hline
\end{tabular}

(BRESSER-PEREIRA, 2001, p. 3)

Sobre o Estado patrimonial, Bresser-Pereira (2001, p. 6) afirma:

São todos burocratas porque sua renda deriva essencialmente do Estado; são patrimonialistas porque os critérios de suas escolhas não são racional-legais, e porque constroem um complexo sistema de agregados e clientes em torno de si, sustentado pelo Estado, confundindo o patrimônio privado com o estatal.

Mais adiante, ainda caracterizando o patrimonialismo estatal, prossegue:

É essa elite política e conservadora que manda de forma autoritária ou oligárquica. Não há democracia. As eleições são uma farsa. A distância educacional e social entre a elite política e o restante da população, imensa. E no meio dela temos uma camada de funcionários públicos, donos antes de sinecuras do que de funções, dada a função do Estado patrimonial de lhes garantir emprego e sobrevivência.

(...)

Antes deles, os testemunhos de Tobias Barreto, Sylvio Romero e Joaquim Nabuco, entre outros, caminham sempre no mesmo sentido. O emprego público, embora não garantisse plena estabilidade, dada a prática das "derrubadas" quando mudavam ministérios de um partido para o outro, era o único emprego possível para uma ampla classe média desempregada. Dela se recrutava a elite política.

Pode-se, imaginar, que os critérios administrativos eram pessoais, e a preocupação com a eficiência da máquina estatal, nula. José Murilo de Carvalho salienta que a "classe média desempregada", a que se referiam Tobias Barreto e Sylvio Romero, formada principalmente de profissionais liberais, em particular bacharéis, e dominantemente mestiços, tinha como vocação o funcionalismo. Não era "a vocação de todos", como exagerou Nabuco, mas era das minorias urbanas, especialmente de seus elementos mais educados e agressivos. (BRESSER-PEREIRA, 2001, p. 7).

Do ponto de vista da história cultural, Sérgio Buarque de Holanda (1995, p. 147-148), descortina em prosa o fundamento sociológico do "homem social", caracterizando-o como avesso à impessoalidade própria das relações estatais, com excesso de afeto próprio das 
relações familiares, resultando na dificuldade de separar o espaço público do privado. Sobre essa a dificuldade cultural do "homem social" na separação entre o público e o privado, o autor afirma:

Não era fácil aos detentores das posições públicas de responsabilidade, formados por tal ambiente, compreenderem a distinção fundamental entre os domínios do privado e do publico. Assim, eles se caracterizam justamente pelo que separa o funcionário "patrimonial" do puro burocrata conforme a definição de Max Weber. Para o funcionário "patrimonial", a própria gestão politica apresenta-se como assunto de seu interesse particular; as funções, os empregos e os benefícios que deles aufere relacionam-se a direitos pessoais do funcionário e não a interesses objetivos, como sucede no verdadeiro Estado burocrático, em que prevalecem a especialização das funções e o esforço para se assegurarem garantias jurídicas aos cidadãos.

Reconhecido por Bresser-Pereira (2001, p. 6) como primeiro escritor a empregar a expressão patrimonialismo como modelo de gestão estatal do Brasil, Holanda (1995, p. 146) ao descrever qual a razão da perpetuação dessa mazela secular, demonstra que além da afetuosidade familiar, que degrada a impessoalidade da coisa pública, há o modelo pessoal da acessibilidade:

A escolha dos homens que irão exercer funções públicas faz-se de acordo com a confiança pessoal que mereçam os candidatos, e muito menos de acordo com as suas capacidades próprias. Falta a tudo a ordenação impessoal que caracteriza a vida no Estado burocrático. O funcionalismo patrimonial pode, com a progressiva divisão das funções e com a racionalização, adquirir traços burocráticos. Mas em sua essência ele e tanto mais diferente do burocrático, quanto mais caracterizados estejam os dois tipos.

No Brasil, pode dizer-se que só excepcionalmente tivemos um sistema administrativo e um corpo de funcionários puramente dedicados a interesses objetivos e fundados nesses interesses.

Ainda com intuito de demonstrar, no plano de uma análise histórico cultural, a persistência do modelo de gestão patrimonial no Brasil, pode ser usada como fonte a obra $O s$ Donos do Poder, na qual Raimundo Faoro (1975, p. 734) reconhece que nem o modelo marxista, tampouco o liberal, explicam adequadamente o contexto histórico-cultural do patrimonialismo brasileiro. Nas palavras do autor: "à crítica de fonte liberal junta-se paradoxalmente no mesmo sentido a crítica marxista. O capitalismo antigo - identificado por simplificação de escola, ao feudalismo, ou ao pré-capitalismo - será devorado pelo capitalismo industrial". No mesmo sentido do texto, prossegue o autor:

a realidade histórica brasileira demonstrou a persistência secular da estrutura patrimonial, resistindo galhardamente, inviolavelmente, à repetição, em fase progressiva, da experiência capitalista. Adotou do capitalismo a técnica, as máquinas, as empresas, sem aceitar-lhe a alma ansiosa de transmigrar.

Mais adiante, fazendo um salto secular na análise histórica que nos servirá a título de conclusão parcial, sustenta o autor: "de D. João I a Getúlio Vargas, numa viagem de seis séculos, uma estrutura político-social resistiu a todas as transformações".

Até este momento, identificamos que há um significativo consenso na historiografia sobre a formação administrativa do Estado brasileiro de que o funcionamento da distribuição do poder tipicamente patrimonialista é uma das principais mazelas da gestão pública brasileira.

Pelo que se pôde verificar nesta até aqui é possível explicar porque, pelas características histórico-culturais brasileiras, no âmbito das representações, privilegiar processos meritocráticos seja algo tão superestimado no Brasil. O instrumento concurso 
público historicamente representou a concentração de esforços profissionalizantes da Administração Pública, contrastando com as populares figuras do nepotismo e do clientelismo estatal brasileiro.

\subsection{O ACESSO AO SETOR PÚBLICO BRASILEIRO: UM RETRATO CONTEMPORÂNEO}

É com relativa facilidade que se ilustra a dimensão da prática do "sistema de pistolão"1 na Administração Pública brasileira. Embora significativamente mais difusa nas administrações estaduais e municipais, usaremos exemplos da esfera federal, que é fiscalizada por instâncias mais corpulentas que os demais entes federados. Não é aleatória a escolha da União para ilustrar o que se descreve. A demonstração do âmbito federal que, como dito, sofre uma fiscalização maior, pode dar uma noção ao leitor do que ocorre em maior escala nos estados e municípios brasileiros, o que a um só tempo revela a dimensão potencial do problema e pode instigar levantamentos mais rigorosos sobre essa questão nas demais esferas do Poder Público.

Luiz Carlos Couto (apud BARBOSA, 1996, p. 73), em A luta pelo Sistema de Mérito, obra esgotada a qual não tivemos acesso, apresenta estatísticas da Divisão de Seleção e Aperfeiçoamento do DASP, de 1937 a 1962:

Inscreveram-se em concurso 695.499 candidatos, dos quais compareceram à primeira prova somente 285.852 , logrando habilitação, afinal, apenas 75.1555 , o que equivale a pouco mais de $10 \%$ dos inscritos. Destes, é preciso frisar, alguns não chegaram a ser nomeados e outros, por terem conseguido habilitação em vários concursos, o foram mais de uma vez. Atualmente, o Serviço Público Civil conta com aproximadamente 677.000 funcionários, sendo 312.000 da Administração centralizada e 365.000 da descentralizada, dos quais pouco mais de 100.000 ingressaram através de concursos públicos realizados pelo DASP ou por outros órgãos da administração, que dispunham do seu próprio sistema de mérito. Como facilmente se conclui, as cifras estão a evidenciar que, na batalha das leis, tem saído vencedor o regime do pistolão, com uma diferença superior a 500.000 sobre o seu adversário, o sistema de mérito.

No passado mais remoto foram os chamados extranumerários, em um passado mais próximo, assim como no presente, a terceirização e os cargos comissionados demissíveis ad nutum representam semelhante vitória ao que a pesquisa citada denominou como "sistema de pistolão", isto é, o modelo patrimonialista resistindo ao modelo de mérito.

Passemos ao panorama do quadro contemporâneo. Atualmente, o Brasil ostenta um quadro de ministros do governo federal que não encontra paralelo em outras nações. Em 2014, eram trinta e nove ministérios para empregar toda a base aliada. O jornal Brasil 247 noticiou esse fato da forma seguinte:

\section{PARA QUE TANTOS MINISTROS?}

A questão principal não é o número de audiências. O que importa é o excesso de ministros no Brasil. São 37, brevemente serão 40. Teoricamente, todos colocados no mesmo patamar, a não ser pela ordem de precedência

\footnotetext{
${ }^{1}$ Como o leitor perceberá, em alguns momentos desse ensaio optamos por reproduzir algumas curiosas locuções empregadas pelos autores da temática dos concursos públicos, apesar de pouco usuais em trabalhos acadêmicos, por entender que essa aparente quebra de protocolo reflete a resposta dos pesquisadores à realidade constatada nas respectivas pesquisas.
} 
estabelecida pelas normas protocolares. Mas, na prática, com pesos diferentes na estrutura de governo. Ninguém, com um mínimo de conhecimento de administração, pode achar que uma organização com 40 pessoas subordinadas a uma só possa ser eficiente.

Como acompanhar, supervisionar, controlar e despachar com 40 pessoas? Nenhum presidente de empresa, ou nenhum chefe de organização de qualquer tipo lida diretamente com 40 pessoas.

Os dados podem não ser muito precisos, mas nossa vizinha Argentina tem 15 ministros. O Chile tem 20. A Índia tem 13. Estados Unidos, França e Alemanha têm 15 ministros. A África do Sul se aproxima mais do Brasil, tem 28. (DOYLE, 2011).

Em abril de 2011, o jornal $O$ Globo noticiou que há ministérios do governo federal em que o quantitativo de servidores comissionados chega a $70 \%$ do total. Veja-se:

Governo federal tem ministério com até $70 \%$ de cargos comissionados

BRASÍLIA - Mesmo tendo admitido 115 mil servidores públicos por meio de concurso na gestão do ex-presidente Luiz Inácio Lula da Silva, o governo federal ainda trabalha com uma parcela muito elevada de cargos de confiança em alguns ministérios. Levantamento feito com base em informações do Portal da Transparência revela que, em alguns casos, os cargos comissionados correspondem a $70 \%$ do quadro de funcionários. Esse é o caso do Ministério do Desenvolvimento Social e Combate à Fome (MDS), que tem 586 cargos de confiança para um total de 839 funcionários. Em março, o número de cargos e funções de confiança na administração direta e em autarquias e fundações chegava a 89.550. (ALVAREZ, 2011).

Além da utilização abuso dos cargos em comissão ocupados por não efetivos, também pela terceirização são contornadas as exigências constitucionais profissionalizantes para ingresso na Administração Pública. Helal (2008, p. 65) coloca nestes termos:

Apesar dos avanços trazidos pela Carta de 1988, os grupos de interesse conseguiram (e conseguem) identificar mecanismos para driblar os princípios méritocráticos na ocupação e provimento no setor público: os cargos de confiança, e a utilização de terceirizados, por parte do Estado, em grande parte, são ferramentas usadas para atender a interesses particulares.

Essa prática é tão comumente difundida que, além de pesquisas acadêmicas, a partir de dados oficiais, a impressa denuncia a situação cotidianamente. Para exemplificar, em junho de 2013, a revista Isto é colocou nestes termos:

Embora tenha anunciado um freio de arrumação nos contratos de funcionários terceirizados - um velho drama da administração pública -, o governo Dilma Rousseff tem exibido uma grande dificuldade em cumprir a promessa. Os gastos com terceirização têm aumentado a cada ano e os contratos com empresas criaram uma máquina paralela de governo. Ao responder, na semana passada, a um requerimento apresentado pelo deputado Antônio Reguffe (PDT-DF) ao qual ISTOÉ teve acesso, a ministra do Planejamento, Miriam Belchior, disse que, em 2012, 24 ministérios e a Presidência da República consumiram nada menos do que $\mathrm{R} \$ 4,3$ bilhões em mão de obra terceirizada. O documento mostra ainda uma verdadeira escalada de despesas com terceiros, a despeito de o governo já contar em seus quadros com 23.579 servidores comissionados. O total divulgado é $48 \%$ maior do que o registrado em 2010 e 20,3\% superior ao que foi gasto em 2011. Só no ano passado, o Ministério da Educação gastou com mão de obra contratada R \$ 1,2 bilhão. Foi seguido pela Saúde, com despesa de R \$ 922 milhões e pela Previdência, que desembolsou R $\$ 431$ milhões. Coube à 
Presidência da República o único bom exemplo da diminuição de gastos, que reduziu em 4,8\% os contratos com terceirização entre 2011 e 2012. (TORRES, 2013).

Na tese mencionada, em que Helal (2008, p. 66) examina a estratificação social no setor público, o pesquisador percebe, da mesma forma, a utilização de terceirização da mãode-obra para contornar a exigência de concurso como condição de ocupação de postos de trabalho da Administração, o que, a um só tempo, deteriora a qualidade técnica do serviço prestado à Administração e viola o princípio de ampla concorrência aos cargos. Nas palavras do autor:

No setor público, em especial, tal desmesura é presente, sendo também
utilizada como mecanismo de burla aos preceitos meritocráticos existentes
na letra da lei. Silva e Souza (2004) chamam a atenção para os riscos de se
utilizar a terceirização nas instituições públicas, para fins de apadrinhamento
e como forma de escapar às normas constitucionais que regem o serviço
público. Os autores (2004) questionam ainda o seguinte: se o Estado não
objetiva o aumento constante da lucratividade, competitividade e
produtividade, quais seriam as razões para não oferecer contratos de trabalho
com as garantias trabalhistas que protegem os estatutários? Silva e Souza
(2004) concluem, afirmando que sequer a redução de custos pode ser
comprovada, haja vista os altos preços pagos pelo Governo às empresas de
terceirização, que oferece em troca, muitas vezes, funcionários com baixa
qualificação.

Além de ser utilizado em larga escala para o "apadrinhamento político", ou seja, para contratação precária na Administração em troca de votos, a terceirização mina o perfil institucional da Administração, desconstruindo um fator importante de organização do setor público, a memória institucional.

Se para o Estado interessa a exigência de agentes qualificados para a prestação eficiente do serviço, o que faz preponderar as implicações sociais e políticas do modelo de recrutamento e seleção, as implicações gerenciais se verificam, principalmente, pela inconsistência na qualificação e treinamento do pessoal do setor público em razão das contratações precárias (comissão a não efetivos e terceirização), o que impacta na gestão da informação e do conhecimento da Administração Pública.

Situada histórica e contemporaneamente a questão dos concursos públicos na experiência administrativa brasileira, passemos à análise mais detida da implicação gerencial do modelo patrimonialista de recrutamento e seleção de pessoal, notadamente nas questões relacionadas com a gestão da informação e do conhecimento no setor público.

\section{A GESTÃO DO CONHECIMENTO NA ADMINISTRAÇÃO PÚBLICA}

Datado do ano de 2001, o artigo do professor Martius Rodrigues y Rodrigues pergunta: Gestão do Conhecimento - Mais um modismo? (RODRIGUES, 2001). Essa provocação faz menção aos modismos administrativos que surgem como verdadeiras tábuas de salvação da gestão, mas que nem sempre são levadas a diante. Como desenvolve bem objetivamente o autor em seu artigo, não foi esse o destino da gestão da informação e do conhecimento, conhecida no meio corporativo pela sigla (GIC), da mesma forma que ocorreu com a administração por objetivos (APO) e a qualidade total (QT), todos os métodos consagrados pela gestão organizacional.

Para Ricardo Barbosa (2008), em artigo que explora as origens, polêmicas e 
perspectivas da gestão da informação e do conhecimento, mais do que um modismo, a disciplina está se consolidando em pesquisas e publicações científicas, especialmente porque, no contexto das organizações contemporâneas, a informação e o conhecimento tem recebido cada vez mais atenção de gestores, profissionais e pesquisadores.

Há uma relação de complementariedade entre a gestão da informação e do conhecimento, daí que costumam associá-las constituindo uma só disciplina. Em brevíssima síntese, pode-se dizer que a gestão do conhecimento diz respeito à gestão da informação ou conhecimento registrado. Tem suas origens na documentação, arquivísticae na biblioteconomia. A gestão de conhecimento diz respeito ao conhecimento pessoal, normalmente ligada à gestão de pessoas, recursos humanos e administração.

No quadro a seguir, proposto por Barbosa (2008, p. 19), apresenta-se uma visão integrada da gestão da informação e do conhecimento que pode ser relevante para esse ensaio. Vejamos:

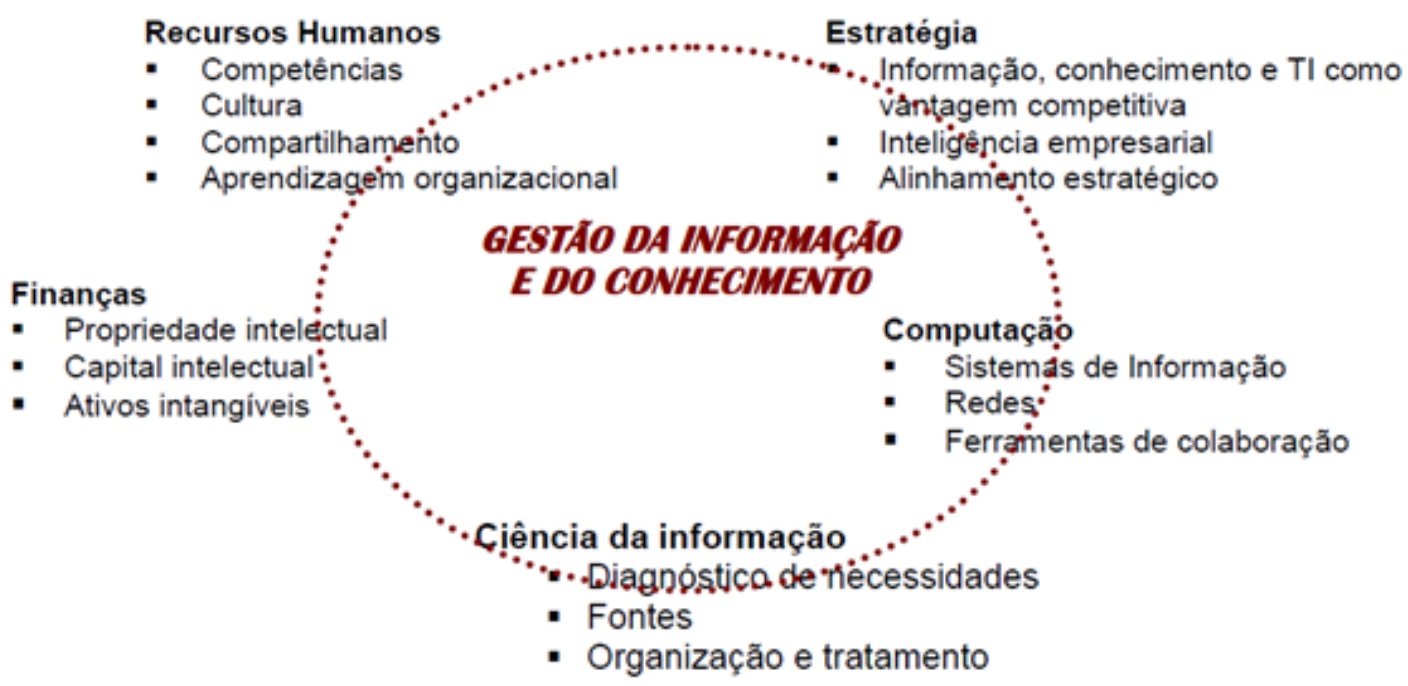

Percebe-se, pela figura, a importância da gestão da informação e do conhecimento nas organizações, inclusive as organizações públicas.

Barbosa anota que uma das abordagens mais antigas sobre gestão do conhecimento é datada de 1974, em que, em um artigo publicado na PublicAdministration Review, Nicholas Henry definia gestão do conhecimentocomo: “[...] políticas públicas para a produção, disseminação, acessibilidade e uso da informação na formulação de políticas públicas" (HENRY apud BARBOSA, 2008, p. 7). Merece destaque o fato de que Henry se dirigia ao setor público (Administração e Defesa Nacional), ressaltando as "disfunções informacionais" como o excesso de dados e as deficiências da tecnologia da informação para formulação de políticas públicas, que poderiam gerar ruídos no processo decisório.

A preocupação da gestão do conhecimento, portanto, teve como um dos precursores um estudioso voltado à Administração Pública. Isso não se dá ao acaso, e algumas dessas razões receberão atenção por estarem intimamente ligadas ao assunto tratado nesse artigo.

No Brasil, o Instituto Econômico de Pesquisa Aplicada, uma fundação pública federal, desenvolve estudos de gestão da informação e do conhecimento. Dentre outros, foram publicados os seguintes trabalhos: gestão do conhecimento (GC) na administração pública: i) Governo que aprende: gestão do conhecimento em organizações do executivo federal (Texto para Discussão, n. 1022, de junho de 2004); ii) Gestão do conhecimento na administração 
pública (Texto para Discussão, n. 1095, de junho de 2005); iii) O desafio da gestão do conhecimento nas áreas de administração e planejamento das Instituições Federais de Ensino Superior (Ifes) (Texto para Discussão, n. 1181, de maio de 2006); e iv) Gestão do conhecimento em organizações públicas de saúde (Texto para Discussão, n. 1316, de dezembro de 2007)

Esses estudos IPEA, aliás, culminaram na publicação do estudo intitulado"Modelo de gestão do conhecimento para a administração pública brasileira: comoimplementar a gestão do conhecimento para produzir resultados em benefício docidadão", de autoria de Fábio Ferreira Batista. Segundo o autor, além de ser caracterizado pelo ineditismo do ponto de vista teórico, o livro se destina a:

[...]descrever um modelo de GC para a administração pública brasileira formado por seis componentes: $i$ ) direcionadores estratégicos: visão, missão, objetivos estratégicos, estratégias e metas; ii) viabilizadores: liderança, tecnologia, pessoas e processos; iii) processo de GC: identificar, criar, armazenar, compartilhar e aplicar; iv) ciclo KDCA; v) resultados de GC; e vi) partes interessadas: cidadão-usuário e sociedade. (BATISTA, 2012, p. 8)

Como se verifica na descrição dos objetivos, viabilizar lideranças e pessoas mediante um processo de compartilhamento e aplicação da gestão do conhecimento é um dos modelos sugeridos pelo IPEA à Administração Pública Federal. Isso vai ao encontro do que Barbosa afirma acerca da gestão do conhecimento que "A gestão do conhecimento se associa à gestão de recursos humanos uma vez que ela envolve o gerenciamento de competências e talentos pessoais" (BARBOSA, 2008, p.19)

Se para Barbosa "Descobrir, organizar, disseminar e utilizar esse conhecimento de maneira efetiva constitui o grande desafio da gestão da informação e do conhecimento". (2008, p. 22), o traço pessoal afigura-se como relevante elemento descobridor, organizador e disseminador de informações nas organizações, especialmente nos altos escalões, também denominados órgãos de cúpula, uma vez que:

Conceitualmente, ela tem início com um diagnóstico de necessidades de informação por parte da cúpula organizacional, o qual conduz à aquisição da informação que, uma vez organizada e armazenada, é distribuída para seus usuários na forma de produtos e serviços de informação. (2008, p. 20)

Em contraste com as melhores práticas de gestão do conhecimento, o modelo de gestão patrimonialista de recrutamento no setor público, principalmente por meio de cargos comissionados e intermediação de mão-de-obra por meio de terceirizações, o que gera reflexos negativos que serão pontuados no capítulo seguinte.

\section{DAS TRÊS POTENCIAIS IMPLICAÇÕES DO RECRUTAMENTO E SELEÇÃO PATRIMONIALISTA DE PESSOAL DO SETOR PÚBLICO NA GESTÃo DO CONHECIMENTO}

\subsection{MEMÓRIA ADMINISTRATIVA}

A memória administrativa ou institucional consiste no conhecimento, por parte do agente público, do destinatário do serviço - o usuário, do funcionamento da máquina, das rotinas e projetos em curso na Administração Pública.

No livro intitulado "Transparência e opacidade do estado no Brasil: usos e desusos da 
informação governamental", José Maria Jardim desenvolve o tema da gestão da informação e do conhecimento na Administração Pública brasileira. Citando Santos, no contexto da análise da reforma do aparelho administrativo promovida no governo Collor, retrata a relação entre o desmantelamento do serviço público profissionalizado com a corrupção e a impossibilidade gestão da informação:

O processo decisório tornou-se praticamente ingovernável com um fluxo de informações inadministrável, "incompatível com a capacidade geral existente, insuficiente para assegurar a preservação do patrimônio e do interesse público frente aos interesses clientelistas e fisiológicos - sem falar na corrupção direta - que jamais deixaram de se manifestar" (SANTOS apud JARDIM, 1999, p. 109)

Adiante, José Jardim prossegue:

Trata-se de uma estrutura cuja complexidade confunde-se com a sua própria desarticulação. Além disso, nos últimos dez anos, têm sido freqüentes as modificações no organograma federal, gerando alto grau de instabilidade organizacional. Esta situação implica:

· fragilização da divisão de trabalho entre os órgãos;

- baixo índice de acúmulo de experiências, conhecimentos burocráticos e dinâmica organizacional entre os servidores, acarretando, por sua vez, uma frágil "memória administrava" das experiências anteriores (JARDIM, 1999, p. 111)

Por fim, citando o Plano de Reforma Gerencial do Estado arremata:

$\mathrm{Na}$ apresentação do Plano Diretor da Reforma do Estado, o Presidente da República destaca que, entre outras conseqüências nefastas, as reformas administrativas ocorridas após 85 "desorganizaram centros decisórios importantes, afetaram a 'memória administrativa', a par de desmantelarem sistemas de produção de informações vitais para o processo decisório governamental"(BRASIL. MARE, 1995, p. 10). Tal posicionamento pressupõe, portanto, que o chefe do Executivo Federal imprime destaque à memória da Administração Federal e reconhece o papel da informação na condução do Governo. (JARDIM, 1999, p. 146)

No mesmo sentido das afirmações apresentadas, acrescenta Helal:

Convém destacar também que longe de trazer benefícios a esfera pública, a terceirização tem trazido consequiências para os terceirizados e para a própria sociedade como um todo. Bicudo (2003), ao trazer o exemplo da terceirização na Petrobrás, aborda suas implicações sociais, gerenciais e políticas. Na pesquisa da autora (2003), os terceirizados relataram baixos salários, alta rotatividade no emprego, longas jornadas de trabalho, calotes recebidos das empreiteiras, longos períodos de afastamento das famílias e trabalho perigoso. O estudo indica ainda que importantes acidentes nas plataformas petrolíferas nos últimos anos podem ser associados à falta de treinamento e qualificação do crescente número de trabalhadores terceirizados. (HELAL, 2008, p. 66).

Assim, ocupando cargos ou funções a título precário, comissionados não efetivos e terceirizados povoam as três esferas política, nos três poderes, atendendointeresses escusos dos mais variados, refletindo o retrocesso no que diz respeito à memória institucional da administração público, causando prejuízo, e, por vezes, a inviabilização da gestão do conhecimento no setor público. 


\subsection{PRODIGALIDADE NO TREINAMENTO}

Muitos recursos são gastos em treinamento de pessoal que, por ocuparem cargos exclusivamente por vínculos pessoais e políticos, muitas vezes são instáveis, de modo que as exonerações ocorrem da mesma forma que as nomeações, isto é, absolutamente sem a observância de nenhum critério republicano, muito menos critérios técnicos.

Disso decorre que muito dos recursos investidos em treinamento de servidores comissionados não efetivos e de terceirizados são desperdiçados, tanto pela total ausência de vínculo do ocupante do cargo com a função pública que exerce, quanto pelo fato de que, não raras as vezes, o servidor (agente ou cooperado) não reúne os requisitos mais elementares para função a que foi alçado, que não o capital político e a troca de favores.

Sem recursos cognitivos prévios, o profissional sequer apresenta condições de aproveitamento das informações transmitidas em cursos de extensão e aprimoramento, o que, também nesse aspecto, traduz-se em desperdício e mal versação do erário.

\subsection{A CÚPULA ORGANIZACIONAL "POLITIZADA" E A DESCONTINUIDADE DAS POLÍTICAS PÚBLICAS}

Como se verificou no texto de Barbosa (2012, p.20), uma das mais relevantes características da gestão do conhecimento nas organizações é a condução de informações que "uma vez organizada e armazenada, é distribuída para seus usuários na forma de produtos e serviços de informação".

Ocorre que a tradição brasileira é de, ao revés de premiar os melhores servidores efetivos com cargos comissionados, o que representa um incremento de recursos para o servidor mais eficiente, em regra tais cargos são ocupados, quase que na totalidade, por agentes não efetivos comprometidos politicamente com o governante.

Um curioso retrato dessa realidade ocorre até na literatura brasileira. No contexto dessa lógica na escolha dos ingressantes do serviço público, Monteiro Lobato, no conto "O luzeiro agrícola", escreve sobre um ex-poeta a quem a fome conduziu as fileiras estatais procurando um político para pedir emprego. "Este lhe oferece os cargos mais altos e, diante da solicitação do poeta para cargos mais humildes, recebe a resposta: 'mas para estes, só com concurso"”. (BARBOSA, 1996, p. 73).

Fosse apenas na literatura de Monteiro Lobato, ou em um passado distante, que a ocupação da cúpula da Administração Pública se desse por critérios, digamos, pouco republicanos, a gestão pública brasileira talvez fosse reconhecida por ser mais profissional. Um caso recentíssimo e emblemáticoocorrido na Agência Nacional de Aviação Civil que, por se tratar de organização pública que demanda abundante qualificação técnica, ganhou muita repercussão e pode servir de exemplo prático para o que se tenta demonstrar. Veja-se:

O líder do PMDB no Senado, Eunício Oliveira (CE), conseguiu emplacar o genro na diretoria da Agência Nacional de Aviação Civil (Anac). Ricardo Fenelon Júnior é advogado e se casou com a filha do peemedebista há menos de um mês, numa cerimônia em Brasília para 1,2 mil convidados, dentre os quais a presidente Dilma Rousseff.

A nomeação foi publicada no Diário Oficial da União na segunda-feira, mas o advogado ainda terá de passar por uma sabatina no Senado. O genro de Eunício se formou em Direito em 2011 pela Uniceub, uma faculdade particular da capital federal. 
A Associação de Pilotos e Proprietários de Aeronaves (APPA) contestou a indicação. "A possibilidade de nomeação política, baseada na mais asquerosa troca de favores partidários, é por nós, especialistas, veementemente repudiada. Demonstramos nossa total contrariedade a qualquer indicação, para cargo diretivo da agência, de pessoas que não possuam qualificação técnica e elevado conhecimento nesse campo de especialidade", diz uma nota publicada em seu site. (PERON, 2015)

Essa ilustração representa precisamente o diagnóstico desse sistema de aparelhamento do Estado. Segundo Walzer, emulando um discurso democrático os partidos políticos praticam o "sistema de espólio". Nas palavras do autor:

Pode-se elaborar uma defesa democrática das facções ou dos partidos e, depois, do que veio a chamar-se "sistema de espólio", pois, nesse caso, parece que a liberdade de decisão para a contratação de funcionários é exibida pela maioria dos cidadãos: seguirei essa linha de argumentação mais adiante. Mas a luta pelo sistema de espólio foi perdida assim que ganhou esse nome. Os cargos são importantes demais para serem considerados espólio da vitória. Ou as vitórias são transitórias demais, as maiorias instáveis demais, para dar forma ao funcionalismo público de qualquer estado moderno. Pelo contrário, o concurso tornou-se o mecanismo distributivo fundamental - tanto que hoje em dia, num estado como Massachusetts, por exemplo, praticamente o único cargo para o qual não há concurso (à exclusão do governador e de seu gabinete, e de diversos comitês consultivos e reguladores) é o de "operário", e mesmo para ele as normas de contratação são rigidamente supervisionadas. Não restam espólios. Os empregos vêm se transformando continuamente em cargos, em nome da honestidade e da eficiência ("bom governo") e também em nome da justiça e da igualdade de oportunidades. (2003, p. 177)

Sem critérios técnicos objetivos para ocupar os cargos de cúpulas dos Órgãos Públicos e das Estatais, além de prestarem um desserviço à Administração Pública como um todo, especialmente no que toca o desestímulo de profissionais prodigiosos, essa prática também interfere na descontinuidade dos critérios de planejamento e execução de políticas pública, considerando que é prática comum o substituto não prestigiar o legado do substituído.

Essas são, em suma, as implicações gerenciais que se reportam exatamente à possibilidade de substituição do critério impessoal e moralizante do concurso público pela institucionalização do modelo de "apadrinhamento político" como sistema de recrutamento de pessoal para cargos comissionados não efetivos e terceirização para intermediação de mão-deobra.Em suma, foram identificadastrês potenciais implicações negativas dos modelos patrimonialistas adotados na ocupação dos postos de trabalhos no setor público podem produzir no que diz respeito à gestão da informação e do conhecimento na Administração Pública.

\section{CONCLUSÃO}

O presente trabalho procurou demonstrar as implicações do modelo de gestão estatal patrimonialista que caracteriza secularmente o setor público brasileiro e sua influência negativa na adoção de mecanismos avançados de gestão pública como a gestão da informação e do conhecimento (GIC). 
Uma característica detectada pela breve contextualização histórica demonstrou que a cultura patrimonialista tem caracterizado de modo singular a gestão institucional brasileira ao longo dos séculos, flagelando todo o sistema público pela ausência de impessoalidade. Essa cultura secular ainda permanece inalterada nas gestões contemporâneas, o que demonstra que esse problema é endêmico, e que a procedimentalização do concurso público nunca alcançou plenamente o seu papel, sobretudo pela criatividade política em burlar as exigências de concursos públicos, notadamente pelo aparelhamento de órgãos utilizando-se de cargos comissionados e outras contratações precárias, como terceirização ilegal.

Depois de uma contextualização histórica e contemporânea do modo de recrutamento que caracteriza o setor público brasileiro, apresentou-se breve descrição do modelo de gestão da informação e do conhecimento, a partir de textos de especialistas sobre o tema, apontando alguns dos relevantes aspectos desse mecanismo de gestão na implementação eficiente de políticas públicas e gestão institucional do setor público.

No terceiro e último capítulo, conjugando a caracterização do recrutamento de pessoal na Administração pública brasileira com os reflexos da gestão do conhecimento no que concernem os recursos humanos, inferiu-se três implicações negativas do patrimonialismo estatal brasileiro frente à gestão do conhecimento.

O primeiro, apresentando os efeitos contraproducentes da transitoriedade quando do abuso de cargos públicos comissionados não efetivos e da terceirização ilegal na (des)construção da "memória institucional". O segundo, destacando o prodigalidade de investimentos de tempo e treinamento de pessoal contratado a título precário. $\mathrm{O}$ terceiro e último, guardando identidade com a transitoriedade e ausência de critérios técnicos de nomeação, apontou-se a "politização" da cúpula organizacional, inclusive como causa da descontinuidade de políticas pública, em razão da necessidade de desconstrução de um legado do cargo político substituído.

Em síntese, o artigo considerou esvaziadas as propostas de mecanismos de gestão da informação e do conhecimento na Administração Pública brasileira enquanto perdurar o endêmico modelo de gestão patrimonialista no recrutamento de pessoal do setor público prevalecendo sobre o critério impessoal e profissionalizante do concurso público.

\section{REFERÊNCIAS}

ALVAREZ, Regina. Governo federal tem ministério com até $70 \%$ de cargos comissionados. Brasília, 2001. Disponível em: http://oglobo.globo.com/politica/governo-federal-temministerio-com-ate-70-de-cargos-comissionados-2792971. Acessado em 20 jun 2014

BRASIL, PRESIDÊNCIA DA REPÚBLICA (1995). Plano diretor da reformado aparelho do

Estado. Brasília: Câmara da Reforma do Estado. Disponível em http: <www.planalto.gov.br/publi_04/coleção/plondi.htm>

BARBOSA, Lívia. Igualdade e Meritocracia: a ética do desempenho nas sociedades modernas. Rio de Janeiro: Fundação Getúlio Vargas Editora, 1999.

Meritocracia à brasileira: o que é desempenho no Brasil? Revista do Serviço Público, Brasília, v. 120, n. 3, ano 47, p. 58-102, set./dez. 1996.

BARBOSA, Ricardo Rodrigues. Gestão da informação e do conhecimento: origens, polêmicas e perspectivas/Gestión de información y del conocimiento: origen, polémicas y perspectivas. Informação \& Informação13.1esp (2008): 1-25.

BATISTA, Fábio Ferreira. Modelo de gestão do conhecimento para a administração pública 
brasileira: como implementar a gestão do conhecimento para produzir resultados em benefício do cidadão/Fábio Ferreira Batista. - Brasília: Ipea, 2012.

BRESSER-PEREIRA, Luiz Carlos. Burocracia pública e classes dirigentes no Brasil. Revista de Sociologia e Política, Curitiba, n. 28, p. 9-30, jun. 2007. Disponível em: <http://dx.doi.org/10.1590/S0104-44782007000100003>. Acesso em: 20 jun. 2013.

Capitalismo dos técnicos e burocracia. Revista Brasileira de Ciências Sociais, São Paulo, v. 20, n. 59, p. 133-171, 2005. Disponível em: <http://www.scielo.br/pdf/rbcsoc/v20n59/a09v2059.pdf>. Acesso em: 30 jun. 2013.

Do Estado Patrimonial ao Gerencial. In: SACHS, Ignacy; WILHEIM, Jorge; PINHEIRO, Paulo Sergio (org.). Brasil: um século de transformações; v. 1. São Paulo: Cia. das Letras, 2001, p. 222-259.

DICIONÁRIO Priberam da Língua Portuguesa. Lisboa: Priberam Informática, 2008. Disponível em: <http://www.priberam.pt>. Acesso em: 6 set. 2013.

DOYLE, Hélio. Para que tantos ministros?.Brasil 247, 12 abr. 2011. Disponível em: <http://www.brasil247.com/pt/247/brasil/1176/Para-que-tantos-ministros.htm>. Acesso em: 4 ago. 2014.

FAORO, Raymundo. Os Donos do Poder. 2. ed. Porto Alegre-São Paulo: Editora Globo: Editora da Universidade de São Paulo, 1975.

HELAL, Diogo Henrique. A dinâmica da estratificação social no setor público brasileiro: meritocracia ou reprodução social?. 2008. Tese (doutorado em Ciências Humanas: Sociologia e Política) Universidade Federal de Minas Gerais, Belo Horizonte/MG. Disponível em: <http://www.bibliotecadigital.ufmg.br/dspace/bitstream/handle/1843/VCSA-7FZV43/tese_ve rs_o_final.pdf?sequence=1>. Acesso em: 20 de jun. 2014.

HOLANDA, Sérgio Buarque de. Raízes do Brasil. 25. ed. São Paulo: Companhia das Letras, 1995.

JARDIM, José Maria. Transparência e Opacidade do Estado no Brasil: usos e desusos da informação governamental. Niterói: EDUFF, 1999.

MENEZES, Igor Silva de. O sistema meritocrático do concurso público: um estudo propositivo na administração pública brasileira. 2015. Dissertação (Mestrado Profissional em Justiça Administrativa) Universidade Federal Fluminense, Niterói/RJ.

Concurso Público: reflexões acerca do dever de convocação pessoal dos candidatos. Revista de Direito Público, Londrina, v. 7, n. 1, p. 45-68, 2012. Disponível em: <http://www.uel.br/revistas/uel/index.php/direitopub/article/view/10375/ 10424>. Acesso em: 25 jul. 2013.

PERLINGEIRO, Ricardo. A justiça administrativa brasileira comparada. Revista CEJ, Brasília, ano XVI, n. 57, p. 6-18, maio/ago. 2012. Disponível em: <http://papers.ssrn.com/sol3/papers.cfm?abstract_id=2196803>. Acesso em: 25 jul. 2013.

PERLINGEIRO, Ricardo. Os princípios do procedimento administrativo no Brasil e os desafios da igualdade e da segurança jurídica. Interesse Público - IP, Belo Horizonte, ano 13, n. 68, p. 93-126, jul./ago. 2011. Disponível em: <http://papers.ssrn.com/sol3/papers.cfm?abstract_id=2196857>. Acesso em: 25 jul. 2013.

PERON, Isadora. Senador emplaca genro como diretor da ANAC. Brasília. O Estado de São Paulo. Disponível em: http://politica.estadao.com.br/noticias/geral,senador-emplaca-genrocomo-diretor-da-anac-imp-,1723178. Acessado em 26 jul 2015.

RODRIGUEZ, Martius. Gestão do Conhecimento Mais um modismo?. Comunidade de RH, 
disponível em: http://www.rh.com.br/Portal/Desenvolvimento/Artigo/2797/gestao-doconhecimento--mais-um-modismo.html\#. Acesso em: 26 jul. 2015.

TORRES, Izabelle. Nas sombras, uma gastança de $\mathrm{R} \$ 4,3$ bilhões. Isto é independente, São Paulo, $\mathrm{n}^{\mathrm{o}}$ 2.273, 7 jun. 2013. Disponível em: < http://www.istoe.com.br/reportagens/ 305134_NAS+SOMBRAS+UMA+GASTANCA+DE+R+4+3+BILHOES 2/6>. Acesso em: 4 ago. 2014.

WALZER, Michael. Esferas da justiça uma defesa do pluralismo e da igualdade. São Paulo; Martins Fontes, 2003. 